\title{
REFLECTIONS
}

\section{When Physical and Social Pain Coexist: Insights Into Opioid Therapy}

\author{
Mark D. Sullivan, $M D, P b D^{1}$ \\ Jane C. Ballantyne, $M D^{2}$ \\ 'Psychiatry and Behavioral Sciences \\ University of Washington, Seattle, \\ Washington \\ ${ }^{2}$ Anesthesiology and Pain Medicine, \\ University of Washington, Seattle, \\ Washington
}

\begin{abstract}
The US opioid epidemic challenges us to rethink our understanding of the function of opioids and the nature of chronic pain. We have neatly separated opioid use and abuse as well as physical and social pain in ways that may not be consistent with the most recent neuroscientific and epidemiological research. Physical injury and social rejection activate similar brain centers. Many of the patients who use opioid medications long term for the treatment of chronic pain have both physical and social pain, but these medications may produce a state of persistent opioid dependence that suppresses the endogenous opioid system that is essential for human socialization and reward processing. Recognition of the social aspects of chronic pain and opioid action can improve our treatment of chronic pain and our use of opioid medications.
\end{abstract}

Ann Fam Med 2021;19:79-82. https://doi.org/10.1370/afm.2591.

\section{INTRODUCTION}

U nderstanding emotions only as reactions to pain may not be adequate. Despite the persistent belief that emotions develop in reaction to pain, and that emotional responses worsen as pain becomes chronic, new epidemiological and neuroscientific evidence suggests that the relationship between chronic pain and emotional distress is bidirectional. ${ }^{1,2}$ Physical pain and negative emotions reinforce each other in patient populations and involve activation of the same limbic brain structures. ${ }^{3}$

Social pain - the pain of interpersonal rejection or intentional abusewas not built into earlier models of physical pain and emotion, largely because social pain was seen as distinct and as arising from interpersonal relations rather than intrapersonal mechanisms, and transformed to physical pain only through a process of "somatization." Social pain, which arises from breaking or threatening interpersonal relationships, is now recognized to activate many of the same limbic brain centers that are activated by physical pain. Broken hearts are often more aversive and harder to heal than broken legs. Although strong links between social pain and physical pain have been apparent in primary care populations for some time, ${ }^{5}$ population studies and modern functional neuroimaging — which has demonstrated shared anatomic areas in the brain-have enhanced the scientific basis for these links. ${ }^{6-8}$ In this paper we will examine how social and physical pain interact, and how a better understanding of these interactions can provide insights that lead to better management of chronic pain.

\section{The Stressed Brain}

Recent research suggests that some shared physical and social stress responses arise because of shared processing in the brain. Areas of the brain that have been associated with the relevance and importance of physical pain, including the insula, dorsal anterior cingulate cortex, and ventral prefrontal cortex, have now been found to be similarly activated 
by social exclusion. ${ }^{7,9}$ Whereas physical pain serves as a signal for adaptive responses that promote tissue healing and avoidance of further injury, social pain may prompt adaptive responses that protect against further social rejection..$^{10-13}$ In both cases, the pain serves a necessary protective role, the first against injury, the second against rejection. This is important because many mammalian species, but particularly humans, depend on social groups for their survival and well-being. ${ }^{14-17}$ We have assumed that persistent clinical pain is caused by persistent damage or disease in the painful body part, but this may not be the case for the most common chronic pain syndromes, such as back pain, headaches, and fibromyalgia. The single longitudinal back pain functional magnetic resonance imaging (fMRI) study showed that reward circuit activation (between the midbrain nucleus accumbens and the medial prefrontal cortex) predicted persistence of back pain, not continued activity in somatosensory circuits. ${ }^{18}$ This study and related neuroscience suggest the intriguing possibility that reward systems may be more important than tissue damage in the transition from acute to chronic pain.

These links between reward and chronic pain may reflect the crucial role of the endogenous opioid system in human survival. Early research into the endogenous opioid system tended to focus on known exogenous opioid actions, namely pain relief, and reward. But more recent research suggests that pain relief and reward are simply the most obvious expressions of a complex and integrated stress-modulation opioid system that promotes survival. Many lines of research now suggest a hitherto underrecognized role for endogenous opioids in socialization and group formation. This social role for endogenous opioids becomes increasingly important and complex as we move from non-primate mammals, to non-human primates, and to humans. ${ }^{8,15,19}$ Endogenous opioids support the most important and unique human social functions. ${ }^{19}$

Endogenous opioid systems are crucial for human social bonding, but when damaged, have a role in perpetuating isolation and chronic illness. Targeted social rejection events, which involve the intentional severing of important social bonds, are among the strongest risk factors for both depression and disruption of the opioid system. ${ }^{20,21}$ Non-medical opioid users show stronger stress responses to these events as well as impaired cognitive empathy. ${ }^{22,23}$ Endogenous opioid activity supports human survival by providing (together with dopamine) integrated responses to stress. Not only do opioids play a role in maintaining homeostasis by integrating and balancing aversive input and reward, ${ }^{24,25}$ they also play an important role in counterbalancing the activating effects of corticosteroids and catecholamines during stress. ${ }^{26}$ Animal and human studies, however, have demonstrated that when repeated or extreme stress overreaches the boundaries of normal stress responses, homeostasis is no longer achieved, and allostatic load contributes to stressinduced chronic illness. In attempting to overcome chronic stress, overactivity of endogenous opioid systems may result in increased basal opioid tone, which can manifest as a state of reward deficiency or impaired ability to obtain natural rewards, contributing to social isolation..$^{27,28}$ These states of reward deficiency may contribute to both chronic pain and addiction risk. ${ }^{28}$

\section{The Artificial Dichotomy Between Physical Pain and Social Pain}

The idea that physical or bodily pain is somehow a privileged form of suffering, beyond a person's control or responsibility, arises from the idea that peripheral tissue damage is the mechanical cause of bodily pain This idea works as long as the intensity of pain actually matches the severity of the peripheral nociception, and the peripheral damage can be identified and addressed. This tends to be true in the case of acute or new onset pain. But this is often not the case in persistent or chronic pain. Here, the relationship between peripheral pain generators and the pain experience is not so simple. Physical pain can be heightened and perpetuated by significant or persistent social stress. Social pain can be experienced and presented as physical pain, yet the driver is less nociceptive input, more social stress. The fact that physical pain is thought of as distinct from social pain now seems like an artificial distinction, but it is a distinction that has had enormous impact because it shapes our policy about pain itself, the use of drugs to treat pain, and the regulation of addictive drugs. When we use opioids to treat chronic pain, we often allow social stress to be treated with opioids only when stress is accompanied by physical pain, leaving other treatment of social stress to the mercy of an illicit market.

\section{Opioid Dependence}

The opioid dependence that develops when opioids are used continuously and persistently over the long term (greater than 90 days) can be a serious condition that shares many of the characteristics of addiction. ${ }^{29}$ This persistent opioid dependence should be distinguished from the opioid dependence that arises after short-term opioid treatment, often manifest as a classic withdrawal which will resolve within days. The more serious and protracted form of dependence may be expressed by complex physical and psychological withdrawal symptoms. After prolonged opioid use, withdrawal symptoms can be manifest without completely 
withdrawing the drug. Continuous or mini-withdrawals can arise during prolonged use because psychological and pharmacological factors continuously change the opioid steady state. This complex withdrawal may be expressed as hyperalgesia, hyperkatefeia (heightened negative emotions), reward deficiency, and social withdrawal. ${ }^{30,31}$ This type of dependence can make opioid tapering extremely challenging because the withdrawal can be not only painful but distressing, producing both physical and social pain as discussed above.

Thus, rather than helping the pain for which the opioid was originally sought, persistent opioid use may be chasing the pain in a circular manner, diminishing natural rewards from normal sources of pleasure, and increasing social isolation. To make matters worse, the people who need and want opioids the most, and who choose to use them over the long term, tend to be those with the most complex forms of chronic pain, containing both physical and social elements. We have called this process "adverse selection" because these are also the people who are also at the greatest risk for continuous or escalating opioid use, and the development of complex dependence. ${ }^{32}$ Survival mechanisms that were already compromised by physical and social injury, are compromised further because the exogenous opioid can overwhelm the natural endogenous defenses. This may be one reason that discontinuation of long-term opioid therapy has been associated with suicide and all-cause mortality. ${ }^{33,34}$

\section{Concluding Remarks}

Much has been learned from the opioid epidemic in the United States. Population studies show clearly that people who stay on opioid analgesics long term (only a small minority of those initiated on opioids) tend to reach high doses. These long-term, high-dose patients are much more likely to be treating a combination of physical and social pain as demonstrated by high rates of psychological trauma, post-traumatic stress disorder (PTSD), and depression in this population. We are currently faced with a subpopulation of patients who have been treated with opioids over many years, usually have multiple comorbidities, and have difficulty tapering now that safety considerations have emerged suggesting that tapering is advisable. This has highlighted the fact that opioid dependence, as it arises during long-term pain treatment, has been poorly conceptualized, and is not simply "physical" and easily reversed. We are confused about what to call prescription opioid dependence, worried about using the word addiction, and bound by diagnostic coding that constrains our treatment choices but often does not fit the patients we see. This confusion, combined with the failure to recognize that the brain adapts similarly during long-term medical and non-medical opioid use, ${ }^{35}$ reinforces the idea that medical use is always good, and non-medical use is always bad.

As prescribers of medical opioid treatment, we must recognize that when physical and social pain coexist, long-term opioid therapy is more likely to harm than help. We believe that short-term opioid therapy, lasting no more than a month or so, will and should remain a common tool in clinical practice. But long-term opioid therapy that lasts months and perhaps years should be a rare occurrence because it does not treat chronic pain well, it impairs human social and emotional function, and can lead to opioid dependence or addiction. Pain intensity ratings are not a good guide to the need for opioid therapy since these ratings are highest in patients with a heavy burden of social pain and psychiatric comorbidity who are at increased risk for opioid adverse events like misuse, abuse, and overdose. This insight into the overlap between physical and social pain should help redirect care for these patients away from opioid treatment that may ultimately worsen their underlying distress and social isolation. It should also direct us toward chronic pain care models that do not separate physical pain (as a medical issue) from social pain (as a nonmedical issue). ${ }^{36}$ Multimodal chronic pain care, which has been offered in multidisciplinary pain rehabilitation programs, offers a model for such care ${ }^{37}$ and been adapted to primary care using nurse care managers as are common in diabetes and depression care, ${ }^{38,39}$ but dissemination, implementation, and funding of these programs remains a challenge.

To read or post commentaries in response to this article, see it online at https://AnnFamMed.org/content/19/1/79/.

Key words: endogenous opioid system; social rejection; reward; opioid dependence; addiction

Submitted December 4, 2019; submitted, revised, February 14, 2020; accepted March 10, 2020.

\section{References}

1. Wade JB, Dougherty LM, Archer CR, Price DD. Assessing the stages of pain processing: a multivariate analytical approach. Pain. 1996; 68(1):157-167.

2. Sturgeon JA, Zautra AJ. Social pain and physical pain: shared paths to resilience. Pain Manag. 2016;6(1):63-74.

3. Gureje O, Simon GE, Von Korff M. A cross-national study of the course of persistent pain in primary care. Pain. 2001;92(1-2): 195-200.

4. Croicu C, Chwastiak L, Katon W. Approach to the patient with multiple somatic symptoms. Med Clin North Am. 2014;98(5):1079-1095.

5. Smith RC, Lein C, Collins C, et al. Treating patients with medically unexplained symptoms in primary care. J Gen Intern Med. 2003; 18(6):478-489.

6. Vijayakumar N, Cheng TW, Pfeifer JH. Neural correlates of social exclusion across ages: A coordinate-based meta-analysis of functional MRI studies. Neuroimage. 2017;153:359-368. 
7. Eisenberger NI, Lieberman MD, Williams KD. Does rejection hurt? An FMRI study of social exclusion. Science. 2003;302(5643): 290-292.

8. Panksepp J, Herman B, Conner R, Bishop P, Scott JP. The biology of social attachments: opiates alleviate separation distress. Biol Psychiatry. 1978;13(5):607-618.

9. Craig AD. Significance of the insula for the evolution of human awareness of feelings from the body. Ann N Y Acad Sci. 2011;1225: 72-82.

10. Baliki MN, Apkarian AV. Nociception, pain, negative moods, and behavior selection. Neuron. 2015;87(3):474-491.

11. Iannetti GD, Mouraux A. From the neuromatrix to the pain matrix (and back). Exp Brain Res. 2010;205(1):1-12.

12. Peyron R, Laurent B, García-Larrea L. Functional imaging of brain responses to pain. A review and meta-analysis (2000). Neurophysio Clin. 2000;30(5):263-288.

13. Coenen VA, Schlaepfer TE, Maedler B, Panksepp J. Cross-species affective functions of the medial forebrain bundle-implications for the treatment of affective pain and depression in humans. Neurosci Biobehav Rev. 2011;35(9):1971-1981.

14. Carr DB. Endogenous opioids' primary role: harmonizing individual, kin/cohort, and societal behaviors. Pain Med. 2017;18(2):201-203.

15. Krahé C, Springer A, Weinman JA, Fotopoulou A. The social modulation of pain: others as predictive signals of salience - a systematic review. Front Hum Neurosci. 2013;7:386.

16. Dunbar RI, Teasdale B, Thompson J, et al. Emotional arousal when watching drama increases pain threshold and social bonding. $R$ Soc Open Sci. 2016;3(9):160288.

17. Nummenmaa L, Tuominen L, Dunbar R, et al. Social touch modulates endogenous $\mu$-opioid system activity in humans. Neuroimage. 2016;138:242-247.

18. Hashmi JA, Baliki MN, Huang L, et al. Shape shifting pain: chronification of back pain shifts brain representation from nociceptive to emotional circuits. Brain. 2013;136(Pt 9):2751-2768.

19. Dunbar RI. Bridging the bonding gap: the transition from primates to humans. Philos Trans R Soc Lond B Biol Sci. 2012;367(1597): 1837-1846.

20. Slavich GM, Tartter MA, Brennan PA, Hammen C. Endogenous opioid system influences depressive reactions to socially painful targeted rejection life events. Psychoneuroendocrinology. 2014;49: 141-149.

21. Troisi A, Frazzetto G, Carola V, et al. Variation in the $\mu$-opioid receptor gene (OPRM1) moderates the influence of early maternal care on fearful attachment. Soc Cogn Affect Neurosci. 2012;7(5):542-547.

22. Kroll SL, Williams DP, Thoma M, et al. Non-medical prescription opioid users exhibit dysfunctional physiological stress responses to social rejection. Psychoneuroendocrinology. 2019;100:264-275.
23. Kroll SL, Nikolic E, Bieri F, Soyka M, Baumgartner MR, Quednow BB. Cognitive and socio-cognitive functioning of chronic nonmedical prescription opioid users. Psychopharmacology (Berl). 2018; 235(12):3451-3464.

24. Navratilova E, Atcherley CW, Porreca F. Brain circuits encoding reward from pain relief. Trends Neurosci. 2015;38(11):741-750.

25. White JM. Pleasure into pain: the consequences of long-term opioid use. Addict Behav. 2004;29(7):1311-1324

26. Valentino RJ, Van Bockstaele E. Endogenous opioids: the downside of opposing stress. Neurobiol Stress. 2015;1:23-32.

27. Chaijale NN, Curtis AL, Wood SK, et al. Social stress engages opioid regulation of locus coeruleus norepinephrine neurons and induces a state of cellular and physical opiate dependence. Neuropsychopharmacology. 2013;38(10):1833-1843.

28. Elman I, Borsook D. Common brain mechanisms of chronic pain and addiction. Neuron. 2016;89(1):11-36.

29. Ballantyne JC, Sullivan MD, Koob GF. Refractory dependence on opioid analgesics. Pain. 2019;160(12):2655-2660.

30. Koob GF. Neurobiology of opioid addiction: opponent process, hyperkatifeia and negative reinforcement. Biological Psychiatry. 2019;Accepted manuscript. Avaiable online 12 June 2019.

31. Borsook D. Opioidergic tone and pain susceptibility: interactions between reward systems and opioid receptors. Pain. 2017;158(2): 185-186.

32. Sullivan MD, Howe CQ. Opioid therapy for chronic pain in the United States: promises and perils. Pain. 2013;154(Suppl 1):S94-S100.

33. James JR, Scott JM, Klein JW, et al. Mortality after discontinuation of primary care-based chronic opioid therapy for pain: a retrospective cohort study. J Gen Intern Med. 2019;34(12):2749-2755.

34. Demidenko MI, Dobscha SK, Morasco BJ, Meath THA, Ilgen MA, Lovejoy TI. Suicidal ideation and suicidal self-directed violence following clinician-initiated prescription opioid discontinuation among long-term opioid users. Gen Hosp Psychiatry. 2017;47:29-35.

35. Coloma-Carmona A, Carballo JL, Rodríguez-Marín J, Pérez-Carbonell A. Withdrawal symptoms predict prescription opioid dependence in chronic pain patients. Drug Alcohol Depend. 2019;195:27-32.

36. Moseley GL, Butler DS. Fifteen years of explaining pain: the past, present, and future. J Pain. 2015;16(9):807-813.

37. Kamper SJ, Apeldoorn AT, Chiarotto A, et al. Multidisciplinary biopsychosocial rehabilitation for chronic low back pain: Cochrane systematic review and meta-analysis. BMJ. 2015;350:h444.

38. Kroenke K, Krebs EE, Wu J, Yu Z, Chumbler NR, Bair MJ. Telecare collaborative management of chronic pain in primary care: a randomized clinical trial. JAMA. 2014;312(3):240-248.

39. Dobscha SK, Corson K, Perrin NA, et al. Collaborative care for chronic pain in primary care: a cluster randomized trial. JAMA. 2009;301(12):1242-1252. 